\title{
Agreement Between Working Length Measurements in Primary Teeth Obtained by Radiographs or Apical Locators
}

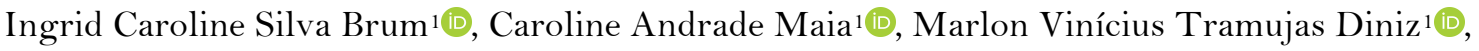 \\ Alexandre Moreira Fernandes ${ }^{2}$ (D) Maria Luiza da Matta Felisberto Fernandes ${ }^{3}(\mathbb{D}$
}

${ }^{1}$ School of Dentistry, University Center Newton Paiva, Belo Horizonte, MG, Brazil.

${ }^{2}$ Department of Endodontics, University Center Newton Paiva, Belo Horizonte, MG, Brazil.

${ }^{3}$ Department of Pediatric Dentistry, University Center Newton Paiva, Belo Horizonte, MG, Brazil.

Author to whom correspondence should be addressed: Maria Luiza da Matta Felisberto Fernandes, Avenida Silva Lobo, 1718, Nova Granada, Belo Horizonte, MG, Brazil. 30431-262. Phone: +55 31 99976-1406. E-mail: marialuizadamatta@gmail.com.

Academic Editors: Alessandro Leite Cavalcanti and Wilton Wilney Nascimento Padilha

Received: 18 March 2019 / Accepted: 25 October 2019 / Published: 13 November 2019

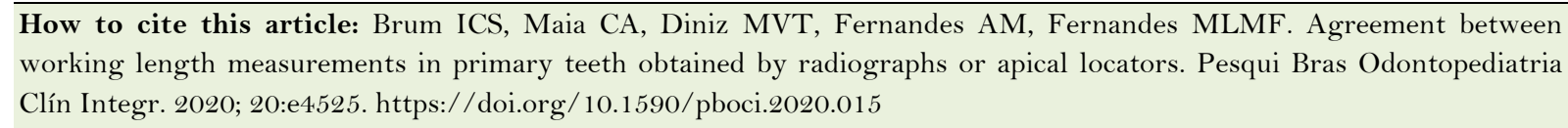

\begin{abstract}
Objective: To perform an in vivo evaluation on the agreement between measurements of working length obtained by conventional radiographic examinations and an apex locator in deciduous teeth with or without root resorption. Material and Methods: Nine canals of teeth from children ranging from 3 to 5 years old were selected. Endodontic access was performed with a spherical diamond tip, the pulp was removed with Kerr-type steel files, and the canal was irrigated with $1 \%$ sodium hypochlorite. A file, compatible with the channel gauge, was then used to measure the length of the root canal with the apex locator. Conventional radiographs were also performed and, using a millimeter endodontic ruler, the length of the canal was determined. The differences between the measurements obtained between the two methods were analyzed using the Student's t-test. Results: The mean canal length for conventional radiography was $9.83 \mathrm{~mm}$ and $9.67 \mathrm{~mm}$ for the apex locator. The results of this study did not show significant differences $(\mathrm{p}=0.641)$, independent of the presence or absence of physiological root resorption. Conclusion: The similarity in measurements obtained with X-ray or an apex locator indicates that it is not necessary to use X-rays as a complement to obtain the working length. The use of the apex locator can provide a quicker treatment, reducing the clinical time and stress of the child.
\end{abstract}

Keywords: Pediatric Dentistry; Tooth, Deciduous; Endodontics; Radiography, Dental. 


\section{Introduction}

A successful endodontic treatment in deciduous teeth plays a fundamental role in the preservation of dentition until the process of physiological exfoliation is completed [1]. In some cases, anatomical variations of the root canals, caused by irregularly occurring reabsorption and the behavior of children during care are factors that impair the success of endodontic treatments [2-5]. The standard method used to determine working length is radiographic examination, which is sometimes difficult to obtain due to the limited access to the children's mouths and their behavior [6,7].

Determining the length of the canal is an extremely important step for an appropriate conclusion of the endodontic treatment, especially in deciduous teeth. The correct establishment of the patent length of the canal will ensure that it is properly instrumented and filled with the obturator material, avoiding possible damages in the periradicular tissues and in the germ of the permanent tooth [8-12].

Radiographic examination presents limitations including overlapping, distortion of the root image and associated structures, such as the permanent germ, exposure to radiation, and inherent difficulties of behaviour management in the case of pediatric dental patients [13,14]. Although the radiographic examination is still the main choice, the apex locator has been presented as a promising method to determine the length of root canals, not only in permanent but also in deciduous teeth [15-19].

Apex locators were developed to determine the working length of root canals without the need of radiation and the first studies on apex locators were published around 1962 [20]. The first and second generation of apex locators presented great disadvantages that directly influenced the success rate in the determination of working lengths, such as the inability to read in the presence of purulent secretions, pulp tissue, irrigators, electrolytes and blood. Third-generation locators met these needs, but they still presented significant disadvantages, such as the need of adjustments made for each use and application only in large and straight canals. These limitations were overcome with the creation of the fourth-generation apex locators, which are used today and provide accurate, painless, quick and easy to operate results, presenting the advantage of verifying the presence of irregular resorptions, which are not observed in conventional radiographs [15,20,21]. Therefore, apex locators have been gaining popularity and are being used in permanent teeth in recent years to estimate working length and increase the precision rates of endodontic treatments [22-25].

The use of the apex locator has been shown to reduce clinical time, aside from avoiding unnecessary exposure to radiation and not causing pain to the patient, which makes its use more favourable for endodontic procedures in pediatric dentistry [26-28]. Studies conducted with different types of apex locators have evaluated their efficiency in deciduous teeth and have obtained satisfactory results, showing that their use can bring advantages to the treatment of deciduous teeth [9,10,16-18,27,28].

The objective of this study was thus, to perform an in vivo evaluation on the association between the working length obtained by conventional radiographic examinations and by using an apex locator in deciduous teeth with or without root resorption. The null hypothesis would be that there is no difference between the measurements determined by either methods.

\section{Material and Methods}

Operator Calibration

An intra-examiner calibration was performed using artificial teeth inserted in irreversible hydrocolloid (Jeltrate, Dentsply Maillefer, Ballaigues, Switzerland) to simulate the patient's natural intraoral tissues. 
Calibration was performed on three teeth over two weeks, and in the first week, conventional radiographs with an exposure time of $0.3 \mathrm{~s}$ were performed to measure the lengths of the canals. After the X-ray processing the artificial teeth were opened with a spherical diamond tip number 1014 for placement of the canals. After a week, a reassessment of the procedure was performed using the same teeth, and the results were compared from one week to the next. A comparison with a gold standard examiner was performed to confirm the results. The intra-examiner agreement reached 1.0, and inter-examiner (comparison with the gold standard) reached 0.97 .

\section{Clinical Study}

Six monoradicular deciduous teeth and one deciduous multi-radicular tooth (with three canals) that needed endodontic treatment were selected. Patients from the pediatric dentistry clinics at the Newton Paiva University Center who needed this type of treatment and who agreed to participate were included in the study.

Before beginning the endodontic treatment, conventional radiographic examinations were performed as a previous diagnostic procedure to determine the measurement of root canal length. The radiographic and apex locator measurements were taken by three calibrated examiners.

\section{Measurements by Conventional Radiography}

To obtain the root canal lengths using the radiographic method, conventional radiographs were performed with the Spectro 70X X-ray apparatus (Dabi Atlante, Ribeirão Preto, São Paulo, SP, Brazil). Radiographic children's films (Insight Infantil IP-01 Periapical Carestream Kodak, Rochester, New York, USA) were used with the parallelism technique aided by a positioner to guarantee precision during the procedure. After the radiographic examination and x-ray processing, the root canal lengths were measured using a millimeter aluminum ruler (Maquira Indústria de Produtos Odontológicos S.A, Maringá, PR, Brazil), supported above the radiograph, positioned in a clinical negatoscope.

Measurements by an Apex Locator

The endodontic apex locator (Gnatus, Ribeirão Preto, SP, Brazil) was used, following the manufacturer's guidelines. A stainless-steel labial clip (Endoprime) was inserted, supported between the lip and the patient's mucous membrane. A $21 \mathrm{~mm}$ K-type file (Kendo München e.V., München, Germany) of a diameter compatible with the apical diameter of the canal was selected, to avoid errors or the absence of reading in the apparatus. After the selected file was attached to the support, it was inserted slowly into the root canal, touching the dentinal walls until the instrument sonically and visually confirmed the contact of the tip of the instrument with the apical periodontal tissues at the "0.0" mark. Then, the silicone slider was moved carefully to the coronary reference point previously established with the aid of a clinical clamp (Golgran Ind. Com. Instr. Odontológicos, São Caetano do Sul, SP, Brazil). Soon after, the file was removed from the canal, the distance between the slider and the tip of the instrument was recorded by an aluminum, millimeter ruler (Maquira Indústria de Produtos Odontológicos S.A, Maringá, PR, Brazil) and thus established the patent length of the canal.

\section{Ethical Aspects}

This study was approved by the Ethics and Research Committee (Protocol No. 31.230-010). Before to the treatment, parents and/or guardians were given a free and informed consent form authorizing the participation of the child in the research. The child was read the term of assent. 


\section{Results}

Measurements of 9 root canals of 7 deciduous teeth of children aged 3 to 5 years, with a median age of 5 years, were evaluated. The following samples were used: 3 canals of tooth 84 of a child. The other teeth were: $51,52,51,51,61$, and 51 with only 1 canal of each tooth of each child. The measurements obtained in each technique for each tooth are presented in Table 1.

Table 1. Length found in each root canal.

\begin{tabular}{cccc}
\hline Tooth & Number of Roots & Tooth Length & Tooth Length in Apex Locator \\
\hline 84 & 03 & D:8 / MB:10/ML: 10 & D:10/ MB:9.5/ ML: 10 \\
51 & 01 & 10.5 & 10 \\
52 & 01 & 8 & 8 \\
51 & 01 & 11 & 11 \\
51 & 01 & 11 & 9 \\
61 & 01 & 10 & 10 \\
51 & 01 & 10 & 9.5 \\
\hline
\end{tabular}

Table 2 shows the mean in millimeters of the values obtained in each of the techniques, the difference between these values and the standard deviation of each group. At the $\alpha=0.05$ level, there was no significant statistical difference between the measurements obtained by the two techniques.

Table 2. Mean and standard deviation for each technique.

\begin{tabular}{cccc}
\hline \multicolumn{1}{c}{ Method Used } & Mean $(\mathbf{m m})$ & SD & p-value \\
\hline Conventional X-ray Measurements & 9.83 & 1.12 & 0.641 \\
Apex Locator Measurements & 9.67 & 0.83 & \\
Difference & 0.17 & 1.03 & \\
Interval (95\% Confidence Rate) of Difference: (-0.626 to 0.959$)$ \\
\hline
\end{tabular}

\section{Discussion}

The success of endodontic treatment in deciduous teeth can be directly influenced by the behaviour management of children, and for this, the dentist has to provide safety, comfort and agility during care to guarantee adequate compliance [3,4]. Another influencing factor in pediatric endodontics is root anatomy, which undergoes physiological reabsorption, which, in many cases, occurs irregularly. Often, these resorptions are not identified in radiographic examinations, leading to treatment failure $[3,6,8,9]$.

The working length determination is a decisive step to avoid possible damage to the germ of the permanent successors and the periradicular tissues because it will avoid over instrumentation or treatment failures if the instrumentation is deficient [6,7]. Currently, the most used method to obtain the work lengths in pediatric dentistry are conventional radiographs. However, there are other methods like digital radiographs and apex locators [3]. The current work seeks to compare root length measurements obtained by the conventional radiographic technique and using apex locators.

Limitations of the radiographic technique include image distortion, the interposition of adjacent structures and defects that occur during the acquisition and processing of radiographs. Besides, another limitation is anatomical variations in the root canals, caused by irregular resorptions, especially on the buccal or lingual surfaces of the root which are often not possible to be located on conventional radiographs, leading to insufficient or excessive instrumentation [9,13,29]. In this study, for the experimental group of conventional radiography we have chosen the parallelism technique, as it is the most reliable method in 
determining the correct measurement of the patent length of the canal. However, due to the behaviour of the children during the radiographic examination, positioning and framing, errors of the studied region are relatively common, generating the need for repetition, clinical time loss and patient stress. In addition, some studies report that the use of this technique may suggest a variation in foramen position or in working length [30,31]. These factors may induce over-instrumentation and/or the overfilling of a deciduous tooth, damaging the permanent tooth $[8,10,11,13,17,32]$.

The first report of the use of an apex locator in the deciduous dentition resulted in similar results compared to real teeth measurements and the X-Ray measurements were longer than to real teeth measurements [19]. Later studies also reported that apex locators in deciduous teeth could present measurements smaller than the actual canal length, detecting differences of up to $3 \mathrm{~mm}$ less. However, these same in vivo studies concluded that the use of locators in teeth with or without root resorption did not present differences $[17,27]$. This latter conclusion was also observed in the present study. On the other hand, contrary to what researchers observed in these in vivo studies, the current study concluded that the measurements demonstrated by the apex locator coincided with the length measured on the radiograph, and there were no statistically significant differences $(\mathrm{p}=0.641)$.

The results of the present study are in accordance with a similar in vitro study that compared the use of conventional radiographs, digital radiographs and the apex locator to determine the working length of deciduous teeth. The authors concluded that the use of the apex locator and digital radiographs are considered safe and accurate methods. They also emphasize that the use of digital radiography is advantageous when compared to conventional radiographs in the endodontics of deciduous teeth, since, with the use of computers, an X-ray with better brightness, contrast and higher image quality can be obtained. In addition, it is much easier to perform repetition when the child's behaviour does not affect the execution of the test. Another advantage would be the elimination of the use of chemicals and less exposure of the child to radiation [14,33]. Despite these advantages, studies did not find significant differences between the conventional radiography method and digital radiography concerning to the measurements obtained [14].

In line with the findings of the present study, other in vivo and in vitro studies with locators in deciduous teeth, with or without root resorption, obtained results indicating that the use of these devices are painless and useful, and they may decrease clinical time and avoid unnecessary exposure to radiation. Therefore, the use of these devices is recommended in deciduous teeth [9,17,19,32,34-36]. In addition, it would be possible for use as a complementary technique to other methods, such as radiographic examination, as it is the initial examination for the diagnosis of the pulp condition and degree of rhizolysis and is indispensable for the decision making as to the best-recommended treatment [18].

Some studies have shown that even in the presence of irrigators, such as sodium hypochlorite or chlorhexidine, saline solution, anesthetic solution, pus and necrotic tissue, locators will still maintain their high level of precision [37,38]. However, to achieve this degree of precision, the operator needs to take into account the anatomy of the root canal, and always be aware of possible variations, such as resorption [24]. Considering the theoretical and practical skills required by the operators, in the present study, intra-examiner training and calibration were performed and reached very good results.

Comparing the two methods, the apex locators can be considered as a good alternative to fill the limitations in using radiographs to obtain working length measurements [39]. The apex locator is fast, comfortable, painless, non-invasive and doesn't expose the patient to ionizing radiation. However, there are still doubts as to whether the accuracy of apex locators can be affected by different types of electrolytes, 
foramen size, pulp vitality and resorption. Small areas with resorption are difficult to identify in radiographic examinations, especially when this resorption occurs on the buccal and lingual surfaces. This can lead to interference in instrumentation and filling. In these cases, the locators may have a reading of the working length less than that found in radiographic examinations, through the contact of the file with the soft tissue of the resorption [9]. Thus, localizers can often broaden the scope of diagnostic possibilities, suggesting variables impossible to be imagined with only radiographic examinations.

Although initial in vitro studies pointed out possible disadvantages of apex locators in deciduous teeth regarding smaller measurements than the actual length, other in vivo studies concluded that the use of locators in teeth with or without root resorption do not present differences [17,27], which is in agreement with the present research. Another study on the efficacy of locators in deciduous teeth with root resorption has shown that even with enlarged foramen, the conical shape of the canal is still preserved [10].

Frequently, because of the time of treatment in the chair, and the behavior of the child, the measurement of the Work Length is taken through the initial radiography, as was done in this study. Due to this, the results found also suggest the use of the apical locator as something more, to confirm the measurement of the radiographic examination and perhaps to help detect the presence of resorption, which are often more difficult to see in the radiograph.

Despite the use of the locator having the advantage of not exposing the patients to the radiation released by the radiographic examination, among others, its use does not diminish the performance of the initial radiographic examination, which serves to provide a correct diagnosis, evaluate the level of root resorption and indicate the position of the deciduous tooth in relation to the germ of the successor tooth.

In the present study, the measurements obtained by the apex locator and the conventional radiographic examinations did not show significant statistical differences. This result suggests that, in order to determine the patent length of the deciduous canal, the use of the apex locator can substitute the conventional radiography with advantages, although the radiographic examination is still used as a gold standard to determine the working length of deciduous teeth.

\section{Conclusion}

No statistically significant differences were observed between the measurements obtained using the Gnatus apex locator and the conventional radiographic examination. Thus, it was possible to conclude that the radiographic examinations can be substituted by the apex locator in the odontometric stage.

\section{Authors' Contributions}

\begin{tabular}{|c|c|c|c|}
\hline ICSB & (iD) $0000-0003-2608-3230$ & $\begin{array}{l}\text { Conceptualization, Methodology, Investigation, Formal Analysis, } \\
\text { Original Draft Preparation and Writing - Review and Editing. }\end{array}$ & Writing \\
\hline CAM & (iD) $0000-0002-0751-5053$ & $\begin{array}{l}\text { Conceptualization, Methodology, Investigation, Formal Analysis, } \\
\text { Original Draft Preparation and Writing - Review and Editing. }\end{array}$ & Writing \\
\hline MVTD & (iD) $0000-0002-5778-0998$ & $\begin{array}{l}\text { Conceptualization, Methodology, Investigation, Formal Analysis, } \\
\text { Original Draft Preparation and Writing - Review and Editing. }\end{array}$ & Writing \\
\hline $\mathrm{AMF}$ & (iD) $0000-0001-6928-2024$ & $\begin{array}{l}\text { Conceptualization, Methodology, Investigation, Formal Analysis, } \\
\text { Original Draft Preparation and Writing - Review and Editing. }\end{array}$ & Writing \\
\hline MLMF & (iD) $0000-0002-5120-1449$ & $\begin{array}{l}\text { Conceptualization, Methodology, Investigation, Formal Analysis, } \\
\text { Original Draft Preparation and Writing - Review and Editing. }\end{array}$ & Writing \\
\hline
\end{tabular}




\section{Financial Support}

None.

\section{Conflict of Interest}

The authors declare no conflicts of interest.

\section{References}

[1] American Academy of Pediatric Dentistry. Guideline on pulp therapy for primary and young permanent teeth. Pediatric Dent 2008; 30(7):170-74.

[2] Guedes Pinto AC, Santos, EM. Tratamento endodôntico em dentes decíduos. In: Guedes Pinto AC. Odontopediatria. $8^{\text {th }}$. ed. São Paulo: Saraiva, 2010. p. 589-612. [In Portuguese].

[3] Mello-Moura ACV, Borelli T, Matos R, Bonini GC, Moura-Netto C. How can we optimize endodontics in primary teeth? a reported case. Rev Assoc Paul Cir Dent 2012; 67(1):50-5.

[4] Goerig AC, Camp JH. Root canal treatment in primary teeth: a review. Pediatric Dent 1983; 5(1):33-7.

[5] Assed S, Freitas AC, Silva LA, Nelson-Filho P. Tratamento endodôntico em dentes decíduos. In: Leonardo M.R. Endodontia: tratamento de canais radiculares princípios técnicos e biológicos. $4^{\text {th }}$. ed. São Paulo: Artes Médicas. 2005; p. 167-232. [In Portuguese].

[6] Nelson-Filho P, Romualdo PC, Bonifácio KC, Leonardo MR, Silva RA, Silva LA. Accuracy of the iPex multifrequency electronicapex locator in primary molars: an ex vivo study. Int Endod J 2011; 44(4):303-6. https://doi.org/10.1111/j.1365-2591.2010.01827.x

[7] Silva EJ, Herrera DR, Souza-Junior EJ, Rosa TP. Evaluation of the multifrequency electronic apex locator Joyapex 5 in primary teeth. Eur Arch Paediatr Dent 2014; 15(1):51-4. https://doi.org/10.1007/s40368-013-0065-0

[8] Mello-Moura AC, Moura-Netto C, Araki AT, Guedes-Pinto AC, Mendes FM. Ex vivo performance of five methods for root canal length determination in primary anterior teeth. Int Endod $\mathrm{J}$ 2010; 43(2):143-7. https://doi.org/10.1111/j.1365-2591.2009.01667.x

[9] Mente J, Seidel J, Buchalla W, Koch MJ. Electronic determination of root canal length in primary teeth with and without root resorption. Int Endod J 2002; 35(5):447-52.

[10] Angwaravong O, Panitvisai P. Accuracy of an eletronic apex locator in primary teeth with root resorption. Int Endod J 2009; 42(1):115-2 1. https://doi.org/10.1111/j.1365-2591.2008.01476.x

[11] Beltrame AP, Triches TC, Sartori N, Bolan M.Electronic determination of root canal working length in primary molar teeth: an in vivo and ex vivo study. Int Endod J 2010; 44(3):402-6. https://doi.org/10.1111/j.1365-2591.2010.01839.x

[12] Saraf PA, Ratnakar P, Patil TN, Penukonda R, Kamatagi L, Vanaki SS. A comparative clinical evaluation of accuracy of six apex locators with intraoral periapical radiograph in multirooted teeth: An in vivo study. J Conserv Dent 2017; 20:264-8. https://doi.org/10.4103/JCD.JCD_131_17

[13] Katz A, Tamse A, Kaufman AY. Tooth length determination: a review. Oral Surg Oral Med Oral Pathol 1991; 72(2):238-42. https://doi.org/10.1016/0030-4220(91)90169-D

[14] Subramaniam P, Konde S, Mandanna DK. An in vitro comparison of root canal measurement in primary teeth. J Indian Soc Pedod Prev Dent 2005; 23(3):124-5. https://doi.org/10.4103/0970-4388.16883

[15] Plotino G, Grande NM, Brigante L, Lesti B, Somma F.Ex vivo accuracy of three electronic apex locators: root ZX, elements diagnostic unit and apex locator and ProPex. Int Endod J 2006; 39(5):408-14. https://doi.org/10.1111/j.1365-2591.2006.01095.x

[16] Tosun G, Erdemir A, Eldeniz AU, Sermet U, Sener Y. Accuracy of two electronic apex locators in primary teeth with and without apical resorption: a laboratory study. Int Endod J 2008; 41(5):436-41. https://doi.org/10.1111/j.1365-2591.2008.01389.x

[17] Kielbassa AM, Muller U, Munz I, Monting JS. Clinical evaluation of the measuring accuracy of ROOT ZX in primary teeth. Oral Surg Oral Med Oral Pathol Oral Radiol Endod 2003; 95(1):94-100. https://doi.org/10.1067/moe.2003.99

[18] Leonardo MR, Silva LAB, Nelson-Filho P, Silva RAB, Raffaini MSGG. Ex vivo evaluation of the accuracy of two electronic apex locators during root canal length determination in primary teeth. Int Endod J 2008; 41(3):317-21. https://doi.org/10.1111/j.1365-2591.2007.01366.x

[19] Katz A, Mass E, Kaufman AY. Electronic apex locator: a useful tool for root canal treatment in the primary dentition. J Dent Child 1996; 63(6):414-7.

[20] Sunada I. New method for measuring the length of the root canal. J Dent Res 1962; 41(2):375-85. https://doi.org/10.1177/00220345620410020801

[21] Guimarães BM, Marciano MA, Amoroso-Silva PA ,Alcalde MP, Bramante, Duarte MAH. The use of apex locator in endodontics: a literature review. ROBRAC 2014; 23(64):112-5.

[22] Dunlap CA, Remeikis NA, BeGole EA, Rauschenberger CR. An in vivo evaluation of an electronic apex locator that uses the ratio method in vital and necrotic canals. J Endod 1998; 24(1):48-50.

https://doi.org/10.1016/Soo99-2399(98)802 14-8 
[23] Elayouti A, Weiger R, Lost C. The ability of root ZX apex locator to reduce the frequency of overestimated radiographic working length. J Endod 2002; 28(2):1 16-9. https://doi.org/10.1097/00004770-200202000-00017

[24] Frank AL, Torabinejad M. An in vivo evaluation of Endex electronic apex locator. J Endod 1993; 19(4):177-9. https://doi.org/10.1016/So099-2399(06)80683-7

[25] Fouad AF, Krell KV, McKendry DJ, Koorbusch GF, Olson RA. Clinical evaluation of five electronic root canal length measuring instruments. J Endod 1990; 16(9):446-9.

[26] Bertoli FMP, Bruzamolin CD, Baratto Filho F, Silva DA, Tomazinho FFS, Gonzaga CC, et al. Performance in vitro of apex locators in determining root length in primary molars. RGO 2016; 64(3):244-9. https://doi.org/10.1590/1981-863720160003000013230

[27] Bodur H, Odabas M, Tulunoglu O, Tinaz AC. Accuracy of two different apex locators in primary teeth with and without root resorption. Clin Oral Investig 2008; 12(2):137-4. https://doi.org/10.1007/s00784-007-0157-5

[28] Ghaemmaghami S, Eberle J, Duperon D. Evaluation of the Root ZX apex locator in primary teeth. Pediatr Dent 2008; 30(6):496-8.

[29] Haffner C, Folwaczny M, Galler K, Hickel R. Accuracy of electronic apex locators in comparison to actual length: an in vivo study. J Dent 2004; 33(8):619-25. https://doi.org/10.1016/j.jdent.2004.11.017

[30] Wu MK, Wesselink PR, Walton RE. Apical terminus location of root canal treatment procedures. Oral Surg Oral Med Oral Path Oral Radiol Endod 2000; 89(1):99-100. https://doi.org/10.1016/s 1079-2 104(00)80023-2

[31] European Society of Endodontology. Consensus report of the European Society of Endodontology on quality guidelines for endodontic treatment. Int Endod J 1994; 27(12):115-24.

[32] Khandewal D, Ballal NV, Saraswathi MV. Comparative evaluation of accuracy of 2 electronic apex locators with conventional radiography: An ex vivo study. J Endod 2015; 41(2):201-4. https://doi.org/10.1016/j.joen.2014.10.011

[33] Lozano A, Forner L, Llena C. In vitro comparison of root-canal measurements with conventional and digital radiography. Int Endod J 2002; 35(6):542-50. https://doi.org/10.1046/j.1365-2591.2002.00535.x

[34] Brunton PA, Abdeen D, MacFarlane TV. The effect of an apex locator on exposure to radiation during endodontic therapy. J Endod 2002; 28(7):524-26. https://doi.org/10.1097/00004770-200207000-00009

[35] Demiriz L, Kocak MM, Saglam BC, Kocak S. In vitro evaluation of the accuracy of ProPex II, Raypex 6 and iPex II electronic apex locators in primary molar teeth. J Health Res Rev 2016; 3(2):37-40. https://doi.org/10.4103/2394-2010.184227

[36] Bahrololoomi Z, Soleymani AA, Modaresi J, Imanian M, Lotfian M. Accuracy of an electronic apex locator for working length determination in primary anterior teeth. J Dent 2015; 12(4):243-8.

[37] Fouad AF, Rivera EM, Krell KV. Accuracy of the Endex with variations in canal irrigants and foramen size. J Endod 1993; 19(2):63-7.

[38] Abdullah A, Singh N, Rathore MS, Tandon S, Rajkumar B. Comparative evaluation of electronic apex locators and radiovisiography for working length determination in primary teeth in vivo. Int J Clin Pediatr Dent 2016; 9(2):11823. https://doi.org/10.5005/jp-journals-10005-1346

[39] Bhat KV, Shetty P, Anandakrishna L. A comparative evaluation of accuracy of new-generation electronic apex locator with conventional radiography to determine working length in primary teeth: an in vivo study. Int J Clin Pediatr Dent 2017; 10(1):34-36. https://doi.org/10.5005/jp-journals-10005-1403 